\title{
CAUSALITY AND DETERMINISM IN ECONOMICS
}

\author{
Stavros A. Drakopoulos* and Thomas S. Torrance**
}

\section{INTRODUCTION}

In recent years there has been a growing interest within economics in causality and related concepts, as the crucial place these notions occupy in the discipline becomes more widely appreciated. One clear manifestation of this interest is in the field of econometrics, where debates concerning the nature of causality are increasingly common. For a long period, however, such concepts were thought by most economists to be clear-cut and relatively unproblematic. The reason for this attitude was the dominance of a central unchallenged paradigm.

Although the term is multi-ambiguous, a paradigm is often understood to be a skeletal structure which any explanatory theory should adopt in order to establish its credibility within a particular scientific peer-group. And the paradigm that until recently was virtually unchallenged within economics was determinism. Acceptance of this paradigm amounts to a belief in the existence of a closed explanatory system for the relevant subject area and in the possibility that a researcher can be wholly detached, in a causal sense, from the events being explained. The determinist paradigm originally evolved in the eighteenth and nineteenth centuries as a guide for authoritative explanatory procedures within classical mechanics and thermodynamics, but over time the paradigm came also to be regarded even by those working in psychology and the social sciences as an ideal to be as closely approached as possible.

This paper examines the background and relevance of the concepts of causality and determinism in economics (including econometrics), and also the appropriateness of the dominant deterministic paradigm for the discipline. In particular, after a discussion of the meaning and significance of these concepts and their customary use by economists, the paper questions the entrenched idea that causal reasoning in economics requires the wider vision of determinism. In the light of developments in twentieth century physics, we further argue that determinism is an unsuitable paradigm even for the natural sciences and that thus, even more strongly, it ought no longer to have a prescriptive role for any of the social sciences.

\footnotetext{
* Department of Economics, University of Aberdeen.

** Department of Economics, Heriot-Watt University.
} 


\section{Determinism and Causality}

In essence, determinism is the doctrine that every event is shaped down to the last detail by a prior set of events and conditions. We need at once to distinguish aleatory (or inherent or 'ontological') from epistemological determinism. Aleatory determinism is the assertion of the factual truth of (something like) 'for every event there is some set of antecedent circumstances that completely caused it'; while epistemological determinism is the claim that we can know, or it is possible for us to discover, the determining causes of every event in the universe. (Since, in logic, we cannot truly know something unless it is actually the case, epistemological determinism presupposes the aleatory variety but not vice versa). There is also prescriptive (or paradigmatic) determinism, which amounts to the methodological injunction that no-one should be satisfied with the explanation of the occurrence of an event or phenomenon that falls short of the deterministic model.

When its implications are fully drawn, determinism appears to open the door to omniscience. The astronomer and physicist Pierre-Simon Laplace (1814) was amongst the first to appreciate this possibility. In his own words:

Given for one instant an intelligence which could comprehend all the forces by which nature is animated and the respective situation of the beings who compose it-an intelligence sufficiently vast to submit these data to analysis-it would embrace in the same formula the movements of the greatest bodies of the universe and those of the lightest atom; for it, nothing would be uncertain and the future, as the past, would be present to its eyes.

In the contemporary world, the Laplacean attitude in an almost unchanged form can be most clearly seen in the work of the physical chemist Jacques Monod (1972).

It is worth examining at this point the scientific standing of the statement 'every event has a cause'. As John Watkins (1957, 1958, 1960) shows, this assertion has the status of a contingent proposition: it is neither internally incoherent nor is it true by virtue of being a theorem of pure logic. Epistemologically, the statement is a multiply general proposition; that is, it combines an unrestricted universal clause with an unrestricted assertion of existence. This can be seen if the proposition is spelled out in full and explicitly: 'for any event there exists another event which is its cause'. But because of the universal element the proposition can never be established or verified as true, and because of the existential element the proposition can never be shown to be false. While the statement could be either true or false, there is no possibility we could ever know which of these two alternatives is actually the case. The statement that embodies the central position of determinism is thus one whose truth or whose falsity could never be formally proved. What has happened, is that some scientific systems (chiefly those of Newtonian mechanics) have simply adopted the principle as an underlying-albeit unestablished and unestablishable-presupposition.

Such principles are in reality not empirical but metaphysical in character, 
and should not be confused with particular testable implications of explanatory theories (e.g. 'the specific event $e_{1}$ was produced by the specific phenomenon $p_{1}$ in circumstances $c_{1}$ '). A metaphysical presupposition generally continues to receive support so long as substantive theories resting on it continue to generate predictions and implications that are not controverted or severely damaged by empirical data (which, in the social sciences is most likely to be of a statistical nature).

\section{Causality in Social Explanation}

Before we look at the sequence of episodes by which natural and social scientists came to adopt the principle of determinism, we shall briefly note what is usually understood when causal reasoning is used in the context of social explanation.

At the outset it is important to distinguish between the causation of a particular single phenomenon with its own unique spatial and temporal properties, and the causation of all particular instances of a given kind of event. In the former case we have what we shall call 'singular causality', while in the latter we have 'general causality'.

With singular causality, what we mean by 'cause' is to be explicated in terms of the concepts of necessity and sufficiency (e.g. Hart and Honore, 1959, for a classic exposition). A single event is 'generated' or 'produced' by a set of prior events and initial conditions. We then analyse this situation by saying that while the whole set is sufficient for the occurrence, each member of the set is necessary. In a typical case of a single identified phenomenon, therefore, what is causally sufficient is a set of antecedent events and conditions, while what is necessary for the same phenomenon is that each and every member of the set occur.

Turning now to general causality, we find that if we seek to explain all the particular instances of some one kind of event then we have to pay attention to the question of the plurality of causes. By this we mean that different instances of the same kind of event may be brought about by sets of factors which contain different types of members. To give a schematic illustration: suppose factors $a_{1} b_{1} c_{1} d_{1}$ (i.e. instances of factors of kinds $A B C D$ ) were sufficient to bring about $p_{1}$ (an instance of phenomenon of kind $P$ ), while factors $a_{2} e_{1} f_{1} g_{1}$ and $h_{1} i_{1} j_{1} k_{1}$ were sufficient to cause $p_{2}$ and $p_{3}$ respectively. In this abstract example, no single type of factor (e.g. $F$ ) can be correctly referred to as being necessary for all instances of phenomenon $P$. Factor $f_{1}$ was a necessary condition for the unique event $p_{2}$, but to say this does not by itself imply that the prior occurrence of some instance of $F$ is a necessary condition for the occurrence of any instance of $P$. Following the insightful terminology of John Mackie $(1965,1980), F$ is an example of an INUS condition of $P$. What this means is that while an instance of $F$ is always Insufficient on its own to produce an instance of $P$, an instance of $F$ could be a Necessary part of some set of conditions which, while being $U$ nnecessary, would nevertheless be $S$ ufficient (if 
it should occur) to bring about an instance of $P$ (see also Addison, Burton and Torrance, 1984).

When specific economic and social events are explained with reference to antecedent sets of causal factors, what entitles us to characterise such a sequence as causal rather than coincidental? An answer to this crucial epistemological question was first provided in the eighteenth century by the economist and philosopher David Hume (1738) in the first truly modern analysis of the nature of causality. For Hume, causal and coincidental connections can only be distinguished with reference to a hypothesis as to the specific principles of organisational order that hold within a particular realm of events (Hume, pp.75-76). It does not follow from this that a causal connection must mirror exactly a statable principle of order (or 'law of nature', if we are dealing with purely physical events). We may be justified in saying that at a particular time the set of factors $a_{1} b_{1} c_{1} d_{1}$ caused $p_{1}$, without committing ourselves to the existence of a universal principle that instances of $A B C D$ are always followed by an instance of $P$. What a specific causal explanation does reflect, however, is an adherence to a belief in the existence of some underlying principles of order (of a sort appropriate to the subject-matter in question), from which, in conjunction with the facts of, for instance, $a_{1} b_{1} c_{1} d_{1}$ we can infer the occurrence of $p_{1}$.

On this view of causality (which we can describe as Hume modified by Mackie), causal explanations emphatically do not usually refer to visible surface regularities of the sort 'an event of kind $F$ is invariably followed by an event of kind $P$ '. More commonly, explanations will refer to deeply-embedded bundles of interacting causal principles, and will thus have to take serious account of the overall environmental setting in which each particular state of affairs to be explained is actually situated.

Mackie's analysis of causality, like Hume's, rests on an 'ontology' of events; that is, the analysis rests on the metaphysical presupposition that all perceptible phenomena can be explained by reference to a foundational realm of causallyordered events. In recent years this presupposition has come under challenge from the Critical Realist school of economists at the University of Cambridge. This school argues that, regardless of whether we are dealing with physical or social phenomena, the ultimate referents of explanation should not be events but rather generative structures with enduring tendencies to function in certain ways in certain types of setting.

In a recent paper the leading figure of the Critical Realist school, Tony Lawson, encapsulates the heart of this approach as follows:

Laws, for the realist, ... are ascriptions of tendencies to certain kinds of things-they describe how generative structures behave. Now such tendencies do not, in general, lead to regularities at the level of events because they will typically be juxtaposed with tendencies of other structures (Lawson, 1989, p.63).

On the Critical Realist programme, we find no difficulty in readily accepting its realist basis: the philosophical standpoint that economics is an explanatory 
science whose primary task is the search for truth concerning the entities and causal connections that actually exist. (In the context of Lawson's paper (p. 60f), 'realism' is to be contrasted with 'instrumentalism', the methodological position that the main aim of economics is to produce reliable predictions without essential regard for the veracity of the theory employed for the purpose).

Also, we agree with the Critical Realist school in maintaining that causal explanations of economic phenomena almost always have to go behind the surface of perceptible events and to discover the underlying reasons for their emergence. We do not, however, in this task, see any special advantage in adopting an ontology of generative structures-with-tendencies rather than of low-level causally-connected events. An 'event' is simply a change in an entity of some kind; and since tendencies and dispositions only become manifest when the possessing entity encounters a relevant change in its environment, we feel it is philosophically satisfactory to view such events themselves, along with their immediate consequents, as being the primary source of causal order.

If, then, within an ontology of events, it is accepted that the fitting way to analyse the causal relation is by reference to the categories of sufficiency and necessity (including Mackie's derivative notion of an INUS condition), the question immediately arises whether these notions themselves implicitly draw strength from the deterministic paradigm. Especially, we want to ask if the notions of 'sufficient condition' and 'necessary condition' can still adequately play the role we have assigned them in the explication of causality if the (unprovable but irrefutable) doctrine of determinism is rejected.

With respect to practice in economics, some writers-most notably Hayek (1967)-have observed that human and social phenomena are 'complex' in the sense that individual events are brought about by a large number of causal factors of different kinds. And faced with this situation, economics resorts to what Hayek calls 'explanation of the principle'. The idea here is that the sheer number and variety of the factors responsible for bringing about a specific social event makes it possible for the social scientist to seek only the main or most powerfully operative causative factors at work prior to the occurrence of the phenomenon under examination. By doing this, an economist is typically able to give a qualitative account of why a particular event should have appeared at the time it did, but would not be able to explain all the quantified aspects of the event itself.

Hayek's argument here is epistemological in character. It says, in effect, that in economics the typical situation is one where limitations of knowledge as to the variety of all the lesser factors at work preclude us obtaining as an explanation a set of complete causal antecedents; in economics, as a matter of practicality, theories have to be confined to dealing with just the main causal factors at work.

It is difficult to fault Hayek's point, but, in itself, it does not do anything to blunt the possible objection of a convinced determinist that better and more precise information would enable economics to push beyond 'explanations of the principle' to 'explanations of detail'. This determinist argument is that 
superior knowledge would enable us to discover currently 'hidden variables' which would allow us to demonstrate that even the smallest detail of any given social phenomenon could be fully explained by reference to prior events and conditions. The determinist would thus claim that Hayek produces an effective argument against epistemological determinism but one which on its own does not damage aleatory determinism.

We shall show in due course that the 'hidden variables' argument in favour of the determinist paradigm is no longer convincing in the light of the way modern theories in micro-physics are perceived, and if the paradigm is implausible in that context it is unlikely to be otherwise within economics or any of the other social sciences.

\section{The Origin of the Modern CONCEPT OF CaUSALITY}

Modern consideration of the nature of causality begins, as noted previously, in the eighteenth century with David Hume. Hume (1738) challenged the mediaeval (rationalist) notion that causal relations were a species of logical relations, and contended instead that causal knowledge could only be empirical: 'it is evident cause and effect are relations of which we receive information from experience, and not from any abstract reasoning or reflection' (Hume, p. 69). For Hume, a causal relation was to be analysed into three components: the temporal priority of the cause to the effect; the immediate or mediate spatial contiguity of the cause to the effect; and the fact that any particular sequence of cause and effect was an instance of a connection of like events that had been regularly observed in the past.

This last element, the regularly observed past constant conjunctions of 'cause' and 'effect', led Hume to identify what we now call the 'problem of induction'. Although for all causal reasoning it is essential to assume 'that instances, of which we have had no experience, must resemble those of which we have had experience, and that the course of nature continues always uniformly the same' (Hume, p. 89), this crucial proposition cannot be established by either logical or empirical argument.

Hume's 'solution' to the problem that there appeared no justifiable basis for the formation of universal principles of order, was to make causality essentially subjective. He argued (Hume, p. 97) that the human mind tends to establish psychological connections between one observation and another and that these mental feelings, by a process of transference, are then read into the events themselves.

Although Hume's final conclusion that causal relationships exist only subjectively did not find later support, the rest of his analysis provided the base from which subsequent analysis started.

\section{J. S. MILl AND PositivisM}

In the nineteenth century, Mill's conception of the issue of causality represents a turn towards a narrower and more dogmatic view (and one which refused to 
embrace Hume's scepticism as an escape from the central problem). Without philosophical justification, Mill resorts to the notion of a 'universal law of causation' and thus 'solves' the problem of induction by introducing the idea of uniformity of nature as a pivotal axiom in every causal explanation (Mill, 1970, pp. 211-12; Blaug, 1980, p. 71). This move brings closer the explicit idea of determinism. And in a clear echo of Laplace, Mill writes:

If we could determine what causes are correctly assigned to what effects, and what effects to what causes, we should be virtually acquainted with the whole course of nature. All those uniformities which are mere results of causation might then be explained and accounted for; and every individual fact or event might be predicted, provided we had the requisite data, that is, the requisite knowledge of the circumstances which, in the particular instance, preceded it (Mill, in Fletcher, 1971, p. 63).

Mill's thought was influenced by the emerging positivism and especially by the positivism of the French sociologist and philosopher Auguste Comte. At the time that Mill was writing, the positivist movement had gathered momentum. The basic idea of positivism was the belief in the scientific method of physical sciences. Comte for instance thought that natural sciences are value free and that their theories are the results of direct generalisations from data. He also believed that in the unity of all sciences and that all sciences, physical or social, are branches of just a single science and should hence have a common scientific method (Lewes, 1978, p. 10). This idea is related to the concept of the degree of positivity of sciences, under which sciences are judged according to their ability to establish universal laws and to predict future phenomena. For instance, positive astronomy, which is based on the Newtonian law of gravitation, was regarded as the model of positivity. Positive astronomy was held to be a purely deterministic science and this is the reason why Comte admires it (Brehier, 1968, p. 292).

It is clear that Comte and other positivists emphasised general laws and advocated a mechanistic approach (that is, an explanatory paradigm modelled on Newtonian mechanics). It should also be added that he saw the historical development of society as progressing towards a positivist era which would be characterised by the dominance of the scientific way of thinking. This implies a belief in historical determinism. The influence of Comte from Newtonian and classical mechanics in his approach is evident. Moreover, the extreme belief in 'mechanistic explanation' implies a belief in the notion of deterministic causality.

\section{LOGICAL Positivism AND MODERN ECONOMICS}

Logical positivism was a continuation of the spirit of positivism which emerged from the writings of Comte. The exact origin of logical positivism is to be found in the 'Vienna circle': a philosophy of science discussion group founded in 1922 by positivist-inclined scientists and philosophers, and led by Moritz Schlick, Otto Neurath and Rudolph Carnap. This group then influenced other 
philosophers like the Englishman Alfred J. Ayer (the author, in 1936, of one of the most famous expositions of the central tenets of logical positivism, Language, Truth \& Logic).

One of the important points of logical positivism was the idea of a unified science. It was anticipated that the adoption of the logical positivist methodology by all scientific disciplines would eventually result in the unification of all sciences. The 'reduction' of all sciences to one is crucial for the unity of sciences. The first step for the reduction would be the establishment of a common scientific language to be based on the language of the most advanced science, namely, the language of physics (Hanfling, 1981). The logical positivists admitted that the task of their philosophy was the construction of one homogeneous system of laws for the whole of science (Carnap, 1981, p. 128). The universal laws would be deterministic laws very similar to the laws of classical physics.

An important exception to the ranks of economists who conformed to the intellectual temper of the twentieth century was J. M. Keynes. The main theme of $A$ Treatise on Probability (1921) was his rejection of the 'objectivist' notion of probability first conceived at Cambridge University by the mathematicianphilosopher Bertrand Russell, and then later developed within the milieu of the Vienna Circle by Carnap as the 'frequency theory of probability'. For Keynes, probability was properly to be viewed not as an attribute of sequences of events but rather as a property of propositions entertained by human minds.

This emphasis on ideas, beliefs and opinions was a reflection of Keynes' general methodological opposition to any hint of a deterministic reductionism within economics that sought to explain completely the choices and decisions of agents by reference to complexes of physical laws. Causal explanation in economics, according to Keynes, did not rest on physical or 'material' causality, but always involved reference to the attitudes, contentions and anticipations of purposive agents. In sharp contrast to the prevailing academic mood of his era, Keynes' economic method recognises as intrinsic and basic the indeterminacy manifested in such human phenomena as imperfect foresight and unstable expectations (Carabelli, 1988, 1989).

But Keynes apart, from the 1920 s and 1930 s onwards many leading economists became influenced by the general intellectual climate of positivism and reductionism (see, for instance, Robbins, 1932; Lipsey, 1983; and for reviews, Rotwein, 1959; Friedman, 1984; Deane, 1978; McCloskey, 1983). Consequently, this dominant determinist paradigm of the concept of causality was strengthened. One can observe the gradual rise to strength of this version of causality that started with Mill (Blaug, 1980; Boland, 1982). Since the thrust of authoritative opinion had moved in the direction, it is not hard to see that the prevailing conception of social causality became deterministic in nature (Coddington, 1972; Loasby, 1976; Thoben, 1982; Caldwell, 1982; Dow, 1985; Mirowski, 1989a).

It must be noted that in the last few decades economics has acquired a significant statistical orientation, as we shall discuss in the next section, and this has meant that determinist emphasis has become less obvious. In spite of this how- 
ever, the deterministic paradigm itself is still strong. For instance, in Savage's theory, states of nature together with acts determine the consequences so that all uncertainty is carried by the space of states of nature, and acts can be construed as random variables on that space (Savage, 1954; Skyrms, 1988). Thus uncertainty is essentially viewed as epistemic and theoretically reducible, and this is very similar to the Laplacean approach (Lawson, 1985, 1988). Other examples similar to the above are the works of Tinbergen (1955) and Friedman (1976). (For further discussion on uncertainty in economics see Radner, 1968, 1970; Hey, 1979; Davidson, 1983, 1988).

\section{CAUSALITY IN ECONOMETRICS}

In the post war era, econometrics became the new rising subfield in economics. The econometric approach involved a range amount of statistical analysis. This resulted in a more 'statistical' conception of causality (Mirowski, 1989b). Many econometricians felt that there was a need to provide some sort of causality definition which would reflect the statistical aspect and since econometrics is about prediction, the predictability aspect. Thus, many econometricians became sympathetic to Jeffreys' definition of causality which is: 'If we can say with high probability that a set of circumstances will be followed by another set, that is enough for our purposes' (Jeffreys, 1957, p. 190; and also Geiser, 1980).

In the following years there were further contributions on this issue. One of the earliest was that of Herbert A. Simon, who states that 'causal orderings are simply properties of the scientist's model, properties that are subject to change as the model is altered to fit new observations' (Simon, 1953, p. 50). The second element in Simon's definition is the idea of the non-necessity of a chronological time ordering between cause and effect. As he writes:

We shall discover that causation (as we shall define it) does not imply time sequence, nor does time sequence imply causation (Simon, 1953, p. 51).

Simon's first point here is understandable insofar as he is concerned to distinguish causal connections from statistical correlations. As Hume first argued, to differentiate a causal from a coincidental relationship the empirically observed connection needs to be associated with a prior or contemporaneous theoretical conception of what might be expected in reality. Without a conception of what might be a principle of theoretical order, one has no grounds for identifying a correlation as causal. What is disputable, however, is Simon's assertion that 'causal orderings are simply [emphasis added] properties of the scientist's model'. But on a realist conception of science, which we briefly discussed in Section III, causal connections are held to have concrete existence (even though we cannot explain precisely what the ultimate essence of such connections amounts to). Thus, on this view, while it is correct to assert, as Simon does, that without a model or theory, a causal connection cannot be identified, it does not follow from this fact that the model is constitutive of the causal connection itself. 
On Simon's second point concerning time sequence, it can be accepted that the assertion of a static functional relationship between two or more variables points atemporally to two or more potential relationships. But once we seek to alter one variable by altering another-and thereby move from a static functional to a dynamic causal relationship-a temporal connotation, assigning priority to the cause, becomes unavoidable. It does not seem to make either scientific or philosophical sense to conceive of an effect occurring before its cause.

Subsequently, Mesarovic (1969) and Katzner (1983) sought to apply and broaden Simon's ideas on causality in economic analysis. A more recent contribution, however, to the issue of causality in econometrics comes from Kevin Hoover, who attempts to extend Simon's approach to causality by generalising it to stochastic, nonlinear systems (Hoover, 1990). Hoover starts by showing that Simon's analysis is consistent with John Mackie's conditional analysis of the causal relation (which we outlined in Section III).

Hoover then proceeds to argue that causal relations cannot be securely identified on the basis of statistical tests alone, but that the process of such identification needs to be carried through in a context of economic theory and knowledge of the relevant economic institutions and general economic background. In particular, Hoover emphasises that the employment of statistical techniques on their own, without prior knowledge of institutions and the economic environment, cannot provide adequate grounds for specifying the direction of causal orderings within the economy. In a further paper, Hoover (1991) demonstrates the application of his approach to the question of the causal direction of the link between money and prices in the United States over the period 1950-1985.

The next important contribution to the discussion of causality in econometric analysis that we should mention is that of Strotz and Wold. They state:

For us, however, the word [causality] in common scientific and statisticalinference usage has the following general meaning. $z$ is the cause of $y$ if, by hypothesis, it is or 'would be' possible by controlling $z$ indirectly to control $y$, at least stochastically (Strotz and Wold, 1960, p. 418).

This definition explicitly links the concept of 'cause' to the concept of 'control': ' $z$ causes $y$ ' means 'control of $z$ yields control of $y$ '. Strotz and Wold also acknowledge that if true, such a statement would not necessarily involve the converse (control of $y$ yields direct or indirect control of $z$ ). This implies that the causal relationship in general cannot be viewed as symmetric. More controversially, they also stress that a putative causal relationship is disproved if both $z$ and $y$ should be subjected to simultaneous and independent changes which then had no respective effects on the other (p. 418).

But recalling Mackie's $(1965,1980)$ analysis where a 'cause' is an INUS condition, there appears to be some confusion in Strotz and Wold concerning the phenomenon of the plurality of causes. If $Z$ (the kind of event of which $z$ is an instance) is an INUS condition of $Y$, it could well happen on occasion that controlled changes applied independently to instances of both of these kinds of 
events would have no repercussions on each other; but this would not establish that, for all possible settings, an instance of $Z$ never features as a causal factor in the appearance of an instance of $Y$. Also, Strotz and Wold do not draw the distinction between 'control of $z$ yields control of $y$ ' as an implication of ' $z$ causes $y^{\prime}$, and the two propositions being identical in meaning. If the latter is indeed intended, then the attribution of causality to a relationship would seem to entail the implicit assumption of a closed system of readily accessible and manipulable variables.

In a subsequent paper, Basmann conceives causality in a similar sense, that is in terms of controlled variables. Also, likewise, he assumes that the relationship under investigation can be isolated from non-random external influences, and that the chain of events in question (what he refers to as 'the mechanism') can be repeatedly started from scratch. If these conditions hold, Basmann defines causality as follows:

If, every time the mechanism is started up from approximately the same initial condition, it tends to run through approximately the same sequence of events, then the mechanism is said to be causal (Basmann, 1963, p. 442).

As with Strotz and Wold, the definition implies the existence, or the possibility of existence, of a closed system. Thus, Basmann's definition and, to a great extent, the Strotz-Wold approach can lead to the development of supposed economic laws which can be used to predict future phenomena (Basmann, 1988).

Granger starts by making two assumptions: that the causal relation in general exhibits chronological asymmetry, and that his conception refers to groups of stochastic processes. He then goes on to give a technical definition of causality as follows:

Let $U_{t}$ be all the information in the universe accumulated since time $t-1$ and let $U_{t}-Y_{t}$ denote all this information apart from the specified series $Y_{t}$. We then have the following definitions.

DEFINITION 1: Causality. If $\sigma^{2}(X \mid U)<\sigma^{2}(X \mid \overline{U-Y})$, we say that $Y_{t}$ is causing $X_{t}$, denoted by $Y_{t} \Rightarrow X_{t}$. We say that $Y_{t}$ is causing $X_{t}$ if we are better able to predict $X_{t}$ using all available information than if the information apart from $Y_{r}$ had been used (Granger, 1969, p. 428).

The basic idea here is that if the variance of the forecast error of an unbiased least squares predictor of a stochastic variable $X_{t}$ based on information $U_{t}$, is smaller than the variance of the forecast error of an unbiased least squares predictor of $X_{t}$ based on information $U_{t}$ without information $Y_{t}$, then $Y_{t}$ is causing $X_{t}$.

Since we cannot obtain knowledge of causality from correlation outside a theoretical framework of some kind, it must be assumed that Granger means his approach to be applied against a background in which several competing causal hypotheses are being examined. Granted this, it is to be noted that Granger appreciates that a literal reading of his definition cannot be satisfactory. His stated definition, as quoted, requires the availability of 'all infor- 
mation in the universe' (represented by the series $U_{i}$ ). In order to escape from the impossibility of seeking to establish a closed causal system, which this expression implies, Granger makes his definition more operational by modifying the 'all available information' [his emphasis] to 'the full set of relevant information' (Granger, 1969, p. 429; also Granger, 1988).

The philosophically important aspect of Granger's conception is its 'open system' approach, which, as will be seen, is close to the preferred assumption of modern physics. Naturally, however, there are a number of practical difficulties with Granger's proposed analysis of the causal relation. First, it is likely that the optimum linear unbiased predictor might not be available. Also, the linear unbiased predictor applies only to finite samples (see Zellner, 1979, pp. 30-35). And, moreover, the above definition of causality excludes all nonstochastic variables. Granger's approach to causality has, however, influenced a number of subsequent econometricians. In particular, Sims refined Granger's approach by stating:

We will give content to Granger's definitions by assuming all time-series to be jointly covariance-stationary, by considering only linear predictors, and by taking expected squared forecast error as our criterion for predictive accuracy (Sims, 1972, p. 544).

What Sims does is to attempt to make Granger's approach more practical by imposing assumptions like linearity. Furthermore Granger-type causality has been applied by a number of econometricians (see for instance, Weaver, 1980; Bessler and Brandt, 1984).

\section{THE NeW SCIENTIFIC PhILOSOPHY OF Physics}

In the first decades of this century there was a revolution in physics which introduced a new conceptual framework and a new scientific philosophy. The main feature of this revolution was that classical physics became just a special case and above all, its methodology was undermined. The two physical theories which were the corpus of this revolution, were special relativity and quantum mechanics (the latter being a theory of atomic- or micro-physics). Since quantum mechanics theorists are the ones who have attempted to construct a new scientific methodology and since a great number of philosophers of science have been influenced by their work, we will concentrate on their account of microphysical reality. Furthermore, most contemporary physicists would accept that the methodological implications of quantum physics does possess universal relevance (Capek, 1961).

\section{Probability, Causality and Uncertainty}

The nature of probability associated with quantum mechanics is revolutionary and different from that of classical physics. For example, the probability of dice throwing with outcome 6 is compatible with the actual outcome 6 . The transition from a less definite state to a more definite one is due to a change 
in knowledge but this transition has no implications for the actual state of the system under consideration (Feyerabend, 1964, p. 246). In quantum mechanics, however, we have a completely different approach:

Consider a measurement where possible outcomes are represented by the states $\phi^{\prime}$ and $\phi^{\prime \prime}$ and which occurs when the system is in a state $\phi=\phi^{\prime}+\phi^{\prime \prime}$. In this case $\phi$ cannot be regarded as an assertion to the effect that one or two mutually exclusive alternatives, $\phi^{\prime}$ and $\phi^{\prime \prime}$ occur, for when $\phi$ is realized physical processes may occur which do not occur, neither when $\phi^{\prime}$ is realized, nor when $\phi^{\prime \prime}$ is realized ... . The transition, on measurement, from $\phi$ to, say $\phi^{\prime \prime}$, is therefore accompanied by a change in physical conditions which does not take place in the classical sense (Feyerabend, 1964, p. 246).

This special nature of probability is sometimes called the 'interference of probabilities' (Heisenberg, 1962, pp. 157-159). It leads modern science to a novel conception of uncertainty. In addition to viewing uncertainty as aleatory (inherent), physicists now tend to argue that uncertainty is in principle irreducible (i.e. the uncertainty does not arise simply for epistemological reasons). To illustrate the point, we can go back to the dice example: the uncertainty of an outcome of dice throwing is reducible because at least in principle we could predict the outcome with absolute certainty, if we knew all the equations and variables involved in the dice motion, à la Laplace. A dice throw is thus not a genuine case of aleatory 'chance' and hence the uncertainty involved is theoretically reducible in the sense of the positivist and/or determinist programmes. This comes about because all the variables involved in the throw of a dice are 'local'. In quantum mechanics these 'local connections' are present too, but apart from them there are also 'non-local connections' which make theoretical certainty impossible even in principle (Heisenberg, 1958, p. 30).

In particular, physics today challenges the 'axiom of contiguity' which establishes the relative independence of objects far apart in space. In other words, the existence of object $A$ has no direct influence on the existence of object $B$ (no local connections). This principle also forms the basis for the existence of closed systems which are essential in classical physics and also in the deterministic framework. However, experimental evidence provided by modern physicists has seriously challenged the principle of contiguity. More specifically the Einstein-Podolsky-Rosen (EPR) experiment was the first one to confirm the existence of nonlocal connections between objects far apart. Einstein attempted to explain the result in terms of 'hidden variables'. However, a few years later, Bell verified the above result and proved the non-existence of hidden variables (for a review see Bell, 1964, and Segre, 1980). It is clear that the existence of non-local connections denies the possibility of closed systems. It also introduces a probabilistic theory of causation which is a non-local theory (Skyrms, 1988). Furthermore, as was seen before, it justifies aleatory uncertainty. Heisenberg states:

The concept of probability and the attendant uncertainty enter theoretically and in principle; they do not refer merely to the theoretical errors, arising 
from the finiteness of, and inaccuracies in, human behaviour ... (Heisenberg, 1958, p. 16).

This state of affairs as described by Heisenberg is to be compared with the uncertainty present in classical thermodynamics which has been a favourite reference of many economists including Paul Samuelson (1966). Thermodynamics had a statistical or probabilistic nature but the molecules of gasses were still assumed to interact in a deterministic way according to classical laws. The uncertainty, on this view, arose because of a supposed technical difficulty: the extremely large number of molecules prevented the calculation of their individual movements. But in spite of the practical difficulties in calculation, the uncertainty present in thermodynamics was held to be reducible in principle (again, an instance of aleatory but not epistemological determinism).

The nature of uncertainty in modern physics is clearly shown through the basic formula of quantum mechanics. If we define $\Delta x$ as the indefiniteness of the position of an electron, $\Delta p x$ the indefiniteness of the momentum, and $h$ as Plank's constant we have:

$$
\Delta x \Delta p x>h / 2 \pi
$$

(Giancoli, 1984, p. 798).

The uncertainty involved here cannot be smaller than a certain measure, and this uncertainty is theoretically irreducible: it has nothing to do with technical difficulties in the way of knowing what is 'really' happening. In particular, it should be noticed, if the uncertainty of position is reduced the uncertainty of momentum increases. Other formulations of this sort of theoretically intrinsic uncertainty relationship include energy and time, and angular momentum and angular position (Feyerabend, 1964, p. 202; Giancoli, 1984, pp. 798-790).

\section{$\mathrm{X}$ IndeTERminacy AND PREDiction}

The above type of aleatory (intrinsic) uncertainty is called indeterminacy by physicists. The main reason for the use of a special word is to distinguish it from the uncertainty that arises on purely epistemological grounds, as is usually the case with the uncertainty found in areas of classical physics. (Bohm, 1957). It is thus obvious that indeterminacy (as defined) is one of the chief points of departure of modern from classical physics. Since indeterminacy, as will be seen, implies ineliminable unpredictability, the credibility of determinism as an appropriate metaphysics for scientific enquiry is radically undermined (Bohr, 1965; Heisenberg, 1958; Segre, 1980, p. 167).

As suggested, the notions of the 'interference of probabilities', probabilistic causation and aleatory uncertainty have important implications for the idea of deterministic prediction which held sway in classical physics. Since aleatory uncertainty is a feature of the make-up of the micro-physical universe, it must be regarded as being pervasive in this domain; but once this is granted, old-style deterministic prediction, as a generally applicable paradigm, is irretrievably damaged. The undermining of the principle of contiguity implies that closed 
systems do not exist and thus deterministic prediction becomes extremely problematic (see for instance, Tambakis, 1984, p. 69, Giancoli, 1984, p. 799 Skyrms, 1988).

Arguments against deterministic prediction as the most important characteristic of the enterprise of science have been put forward by numerous theorists, including Amaldi (1966), Eddington (1964) and Bohr (1965). Following them, it should be stressed that for modern science, inherent uncertainty and unpredictability are not just peculiar characteristics of events within the arena of atomic physics; they are not confined merely to microphysical phenomena but are quite general. For instance, Heisenberg's uncertainty principle is fully applicable when it comes to calculating the simultaneous momentum and position of a bullet travelling on a horizontal course: our attempt to measure one aspect will interfere with the properties of the other. (Of course, such interference at the level of a macro-object such as a speeding bullet would be extremely minute and could usually be disregarded for practical purposes). Thus, in principle, even the behaviour of 'ordinary' objects can only be predicted probabilistically. The replacement of deterministic prediction by probabilistic prediction for reasons other than those that are simply epistemological, is in sharp contrast to the classical or Laplacean idea of absolute predictability being possible in principle. (A further approach worth mentioning, but which we will not explore here, is that the case against the absolute predictability of the classical paradigm, is reinforced by the application of 'Godelian sentences', see Popper, 1950).

The theoretically incomplete separation of object from subject as an element of modern physics is tightly linked with the modern notion of aleatory uncertainty. The phenomenon of the 'interference of probabilities' arises because it is closely connected with the act of observation, in that the process of measurement itself is what affects probabilities (see also Drakopoulos, forthcoming). Heisenberg asserts that '... observation itself changes the probability function discontinuously' (Heisenberg, 1958, p. 54). He then goes on to make some general methodological comments about the consequences of this characteristic of modern physics. In particular, he blames the outmoded separation of object and subject in classical physics as coming from Cartesian modes of thought (Heisenberg, 1958, p. 75).

Other physicists like Born, Bohm and Bohr, the founders of atomic physics, have also supported the above view. Bohr, for instance, believes that observation in physics should be treated in the same manner as interaction between physical elements. In particular, he holds that the objectivity of science is a function of the concepts with which experience is described (Folse, 1985, p. 217; Bohm, 1957; Born, 1964, p. 233).

\section{CONCLUSION}

The deterministic paradigm is essentially rooted in a philosophical or metaphysical conception of the ultimate nature of the universe. In general, if a paradigm tends to 'work' then it becomes reinforced. When, however, new 
empirical theories, devised on a different philosophical basis, prove successful then the old paradigm, whilst not being formally 'refuted', goes into a state of eclipse. This currently appears to be the fate of determinism in the face of successful explanatory theories in modern physics. The ideas of the 'interference of probabilities', indeterminacy, and the complementary of object and subject have seriously discredited the paradigm of determinism, at least in the eyes of most contemporary theoretical physicists. Along with the decline of determinism as the dominant paradigm in physics, the closely associated notion of the closed system has undergone a collapse in prestige.

For economics and the other social sciences, the lesson is unambiguously clear. The social sciences should never aim to mimic the physical sciences in any crude or mechanistic manner (all systematic disciplines have to use modes of enquiry that are appropriate to the kind of events being studied). But for economics to continue to look to the traditional notions of the deterministic paradigm to provide the structure for 'ideal' explanations can only appear today to be obscurantist. Newer ideas such as Hoover's approach (based on Mackie's conditional analysis of the causal relation) or Granger-type notions of causality, built upon the wider conceptions of open systems and of inherently probabilistic explanations, are more likely in future to produce fruitful research results. If determinism is rejected by physics, then it is surely implausible to suggest that the paradigm could be rehabilitated by successfully underpinning theories in economics. The social sciences in any case are not a natural habitat for determinism: in dealing with purposive actions, preferences and decisions, socially meaningful societal events and institutions etc., they are concerned with things that derive their essential significance because they exist in a world of indeterminacy.

\section{REFERENCES}

Addison, J. T., Burton, J. and Torrance, T. S. (1984). Causation, social science and Sir John Hicks. Oxford Economic Papers, 36, pp. 1-11.

AMALDI, G. (1966). The Nature of Matter. London: Allen and Unwin.

AYER, A. J. (1936). Language, Truth \& Logic. London: Victor Gollancz.

BASMANN, R. (1963). The Causal interpretation of non-triangular systems of economic relations. Econometrica, 31 , pp. 439-48.

BASMANN, R. (1988). Causality tests and observationally equivalent representations of economic models. Journal of Econometrics, 39, pp. 69-104.

BeLl, J. (1964). On the Einstein-Podolsky-Rosen paradox. Physics, 1, pp. 195-200.

BESSLER, D. and BRANDT, J. (1982). Causality tests in livestock markets. American Journal of Agricultural Economics, 6, pp. 140-44.

Blaug, M. (1980). The Methodology of Economics. Cambridge: Cambridge University Press.

BонM, D. (1957). Causality and Chance in Modern Physics. London: Routledge.

BOHR, N. (1965). The structure of the atom. In Nobel Lectures in Physics. Amsterdam: Elsevier.

Boland, L. (1982). The Foundations of Economic Method. London: Allen and Unwin.

BORN, M. (1964). Natural Philosophy of Cause and Chance. New York: Dover Publications.

BrehIER, E. (1968). The History of Philosophy: the Nineteenth Century. Chicago: The University of Chicago Press.

(c) Scottish Economic Society 1994 
Caldwell, B. (1982). Beyond Positivism: Economic Methodology in the Twentieth Century. London: Allen and Unwin.

CAPEK, M. (1961). The Philosophical Impact of Modern Physics. Princeton: Van Nostrand.

Carabell1, A. M. (1988). On Keynes' Method. London: Macmillan.

Carabelli, A. M. (1989). Keynes on cause, chance and possibility, In T. Lawson and H. Pesaran (eds) Keynes' Economics. London: Routledge.

Carnap, R. (1981). Protocol statements and the formal mode of speech. In O. Hanfling (ed.) Logical Positivism, Oxford: Basil Blackwell.

Coddington, A. (1972). Positive economics. Canadian Journal of Economics, 5, pp. $1-15$.

Davidson, P. (1983). Rational expectations. Journal of Post Keynesian Economics, 5, pp. $182-198$.

DAvidSON, P. (1988). A technical definition of uncertainty and the long run neutrality of money. Cambridge Journal of Economics, 12, pp. 329-337.

DeAne, P. (1978). The Evolution of Economic Ideas. Cambridge: Cambridge University Press.

Dow, S. (1985). Macroeconomic Thought. London: Basil Blackwell.

DRAKOPOULOS, S. (forthcoming). Economic Method and the Scientific Philosophy of Modern Physics. Journal of Interdisciplinary Economia.

EdDington, A. (1964). The Nature of the Physical World. London: Dent.

Feyerabend, P. K. (1964). Problems of microphysics. In R. Colodny (ed.) Frontiers of Science and Philosophy, London: Allen and Unwin.

FletCHER, R. (1971). John Stuart Mill. London: Nelson.

Friedman, M. (1976). Pricing Theory. Chicago: Aldine Publishing Company.

FOLSE, H. (1985). The Philosophy of Niels Bohr. Amsterdam: North Holland.

GeISSER, S. (1980). The contributions of Sir Harold Jeffreys to Bayesian inference. In A. Zellner (ed.) Bayesian Analysis in Econometrics and Statistics, Amsterdam: North Holland.

Giancoli, D. (1984). General Physics. New Jersey: Prentice Hall.

GRANGER, C. W. J. (1969). Investigating causal relations by econometric models and cross-spectral methods. Econometrica, 37, pp. 424-38.

GRANGER, C. W. J. (1988). Some recent developments in a concept of causality. Journal of Econometrics, 39, pp. 199-211.

Hanfling, O. (1981). Logical Positivism, Oxford: Basil Blackwell.

HART, H. L. A. and Honore, A. M. (1959). Causation in the Law. Oxford: The Clarendon Press.

HAYEK, F. A. (1967). Studies in Philosophy, Politics and Economics. London: Routledge.

Heisenberg, W. (1958). Physics and Philosophy. London: Allen and Unwin.

HeIsenberG, W. (1962). The Physicists' Conception of Nature. London: The Scientific Book Guild.

HEY, J. (1979). Uncertainty in Microeconomics. London: Martin Robertson.

Hoover, K. D. (1990). The logic of causal inference: econometrics and the conditional analysis of causation. Economics and Philosophy, 6, pp. 207-234.

Hoover, K. D. (1991). The causal direction between money and prices, Journal of Monetary Economics, 27, pp. 381-423.

Hume, D. (1738). A Treatise on Human Nature. In L. A. Selby-Bigge (ed.) (1978). Oxford: Oxford University Press.

JefFreYs, H. (1957). Scientific Inference. Cambridge: Cambridge University Press.

KATZNER, D. (1983). Analysis without Measurement. Cambridge: Cambridge University Press.

Keynes, J. M. (1921). A Treatise on Probability. London: Macmillan.

KeYnes, J. M. (1973). The Collected Writings: The General Theory and After, XIV. London: Macmillan.

LAPLACE, P. S. (1814). Essai philosophique sur les probabilities, translated from the sixth French edition by F. W. Truscott and F. L. Emory (1951). A Philosophical Essay on Probabilities, New York, Dover Publications, p. 4.

LAWSON, T. (1985). Uncertainty and economic analysis. Economic Journal, 95, pp. $909-927$. 
LAWSON, T. (1988). Probability and uncertainty, in economic analysis. Journal of Post Keynesian Economics, XI, pp. 66-81.

LAWSON, T. (1989). Abstraction, tendencies and stylised facts: a realist approach to economic analysis. Cambridge Journal of Economics, 13, pp. 59-78.

LEWES, G. (1878). Comte's Philosophy of the Sciences. London; George Bell.

LIPSEY, R. (1983). Positive Economics. London: Weidenfeld and Nicolson.

LOASBY, B. (1976). Choice Complexity and Ignorance. Cambridge: Cambridge University Press.

LOSEE, J. (1980). A Historical Introduction to the Philosophy of Science. Oxford: Oxford University Press.

Mackie, J. L. (1965). Causes and conditions. American Philosophical Quarterly, 4, pp. 245-264.

MackIE, J. L. (1980). The Cement of the Universe: A Study in Causation. Oxford: Clarendon Press.

MCCLUSKEY, D. (1983). The rhetoric of economics. Journal of Economic Literature, XXI, pp. $481-517$.

MESAROVIC, M. D. (1969). Mathematical theory of general systems and some economic problems. In H. W. Kuhn and G. P. Szego (eds) Mathematical Systems and Economics I. Berlin: Springer-Verlag.

Mirowski, P. (1989a). More Heat than Light. Cambridge: Cambridge University Press.

Mirowski, P. (1989b). The probabilistic counterrevolution, or how stochastic concepts came to neoclassical theory. Oxford Economic Papers, 41, pp. 217-35.

MONOD, J. (1972). Chance and Necessity. Transl. by A. Wainhouse, London: Collins.

POPPER, K. R. (1950). Indeterminism in quantum physics and in classical physics. British Journal for the Philosophy of Science, 1 and 2, pp. 117-135, 173-195.

RADNER, R. (1968). Competitive equilibrium under uncertainty. Econometrica, 36, pp. $31-58$.

RADNER, R. (1970). Problems in the theory of markets under uncertainty. American Economic Review, 60, pp. 454-60.

Robbins, L. (1932). An Essay on the Nature and Significance of Economic Science. London: Macmillan.

Samuelson, P. (1966). The Collected Scientific Papers of Paul Samuelson, J. Stiglitz (ed.), Cambridge (Mass.): MIT Press.

SavaGe, L. (1954). The Foundations of Statistics. New York: Dover Publications.

SEGRE, E. (1980). From X-Rays to Quarks. San Francisco: Freeman.

SIMON, H. A. (1953). Causal ordering and identifiability. Studies in Econometric Method. Cowles Commission Monograph No. 14. W. C. Hood and T. Koopmans, (eds). New York: John Wiley.

Sims, C. A. (1972). Money, income and causality. American Economic Review, 62, pp. $540-52$.

SKYRMS, B. (1988). Probability and causation. Journal of Econometrics, 39, pp. 53-68.

StRotZ, R. H. and WOLD, H. (1960). Recursive versus non-recursive systems: an attempt at synthesis. Econometrica, 28, pp. 417-27.

Tambakis, N. (1984). From Physics to Metaphysics. Athens: Zacharopoulos (in Greek).

THOBEN, H. (1982). Mechanistic and organistic analogies in economics reconsidered. Kyklos, 35, pp. 292-306.

WatkIns, J. W. N. (1957). Between analytic and empirical. Philosophy, XXXII, pp. $112-131$.

WATKINS, J. W. N. (1958). Confirmable and influential metaphysics. Mind, LXVII, pp. 344-365.

WATKINS, J. W. N. (1960). When are statements empirical? British Journal for the Philosophy of Science, X, pp. 287-308.

WEAVER, R. (1980). The causal linkage of control policy and its targets: the case of wheat. American Journal of Agricultural Economics, 62, pp. 512-16.

Wold, H. (1960). A generalization of causal chain models. Econometrica, 28, pp. 443-63.

ZELLNER, A. (1979). Causality and econometrics. Journal of Monetary Economics (supplement), pp. 9-54.

Date of receipt of final manuscript: 15 November 1993.

(C) Scottish Economic Society 1994 